\title{
O direito transnacional e a consolidação de um pluralismo jurídico transnacional
}

\author{
Carla Piffer \\ Paulo Márcio Cruz
}

\section{INTRODUÇÃO}

Este escrito pretende discorrer sobre o direito transnacional e a possibilidade de consolidação de um pluralismo jurídico transnacional. Para atingir tal objetivo, inicialmente são tecidas considerações acerca da transnacionalidade como fenômeno caracterizador da sociedade mundial.

Parte-se do pressuposto de que a perspectiva transnacional não possui somente uma pretensão descritiva, mas também jurídica. Ao analisar a transnacionalidade, pretende-se apresentar as mudanças ocorridas nas formas de compreender as ocorrências atuais e, para tanto, adota-se o fenômeno transnacional como ponto de partida para análise da sua dimensão jurídica; e, a partir deste, são apresentados questionamentos acerca das clássicas teorias monistas e dualistas, a fim de evidenciar que as complexas redes de relações jurídicas que operam na esfera transnacional não mais se amoldam às incipientes teorias jurídicas que justificam o monismo e o dualismo

A infinidade de atores envolvidos - estatais ou não-estatais -, e as relações mútuas entre ordens jurídicas em um constante processo de integração

\footnotetext{
* Pós-doutora em Direito pela Universidade de Passo Fundo (UPF), mestra e doutora em Ciência Jurídica pela Universidade do Vale do Itajaí (Univali) e doutora em Direito Público pela Università degli Studi di Perugia, Itália. Professora do Programa de Pós-Graduação Stricto Sensu em Ciência Jurídica da Univali. Bolsista do Programa Nacional de Pós-Doutorado da Coordenação de Aperfeiçoamento de Pessoal de Nível Superior (PNPD/Capes). E-mail: carlapiffer@univali.br.

** Pós-doutor em Direito do Estado pela Universidade de Alicante, na Espanha, doutor em Direito do Estado pela Universidade Federal de Santa Catarina (UFSC) e mestre em Instituições JurídicoPolíticas pela mesma instituição. Coordenador e professor do Programa de Pós-Graduação Stricto Sensu em Ciência Jurídica da Universidade do Vale do Itajaí (Univali). Professor visitante nas universidades de Alicante, na Espanha, e de Perúgia, na Itália. E-mail: pcruz@univali.br.
} 
e coordenação nos dão conta de que as atuais soluções jurídicas limitadas e rudimentares necessitam de uma nova forma.

Por estas razões, vislumbra-se a possibilidade da formação de um pluralismo jurídico transnacional a partir do direito transnacional, que em muito se difere do pluralismo jurídico clássico.

A metodologia a ser empregada compreende o método indutivo, sendo acionadas as técnicas do referente, da categoria, dos conceitos operacionais e da pesquisa bibliográfica.

\section{TRANSNACIONALIDADE: NOVAS LENTES PARA A COMPREENSÃO DA SOCIEDADE MUNDIAL}

Como já afirmava Beck, a sociedade mundial tomou uma nova forma no curso da globalização, relativizando e interferindo na atuação do Estado nacional, pois uma imensa variedade de relações conectadas entre si cruza as fronteiras territoriais estatais, estabelecendo novos círculos sociais, redes de comunicação, relações de mercado e formas de convivência ${ }^{1}$.

Segue o autor afirmando que já vivemos há tempos em uma sociedade mundial, palco onde se entrechocam as diversas formas econômicas, culturais e políticas, e tudo aquilo que parecia ser evidente, carece de uma nova legitimação, notadamente no plano jurídico. Assim, esta sociedade mundial significa o conjunto de relações sociais "não integradas à política do Estado nacional ou que não são determinadas (determináveis) por ela" .

Portanto, mostra-se indiscutível a evidente interdependência entre os Estados bem como entre as mais variadas sociedades. Também não pairam dúvidas de que todos vivenciam uma considerável intensificação das interrelações entre pessoas facilitadas pela redução do binômio espaço-tempo, pois a sociedade mundial não cabe em um único Estado, e portanto, a política deste se mostra desnecessária e ineficaz ${ }^{3}$.

Todas estas características simplesmente demonstram que a sociedade mundial e sua relação com os Estados não possuem um viés estritamente objetivo. Inicialmente, porque conduz à necessidade e possibilidade da emergência de um "Estado mundial"4 que, por possuir esta característica múltipla aceitaria e legitimaria a coexistência das mais variadas relações sociais e culturas em um local livre, ou seja, não restrito à figura de um único Estado nacional. Em segundo lugar, ante à inadequação e impossibilidade de manutenção de um modo de ser único e de um estereótipo homogêneo, que deixou de ser, há tempos, a identificação de um Estado ou das pessoas que nele vivem. Ora, a sociedade mundial designa diversidade e diferença pelo simples fato de ser um emaranhado de relações cada vez mais interconectadas e influenciadas pela globalização. 
Aqui se evidencia a ideia de Wallerstein, no sentido da possibilidade de localizar um sistema-mundo em áreas muito restritas 5 . Devido às mudanças e transformações vivenciadas pelas sociedades e pelos Estados torna-se totalmente possível presenciar e vivenciar a existência de vários sistemas-mundo dentro de um único Estado que, por vezes coincidem com a figura nacional e por vezes não, ou seja: tal Estado é composto, singelamente, por diferenças, diversidades e variedades que não são as responsáveis diretas pela sua crise nem mesmo pelos problemas que afetam o seu mal-estar contemporâneo.

"Em linhas gerais, não é mais possível entender tais conceitos em suas versões clássicas, se é que ainda são conceitos operacionais para descrever esta experiência institucional"'. Isso porque o Estado foi, e continuará sendo, fortemente afetado pelo fenômeno da transnacionalidade, ante a verificação da intensificação de relações ditadas pela globalização e suas dimensões. Consequentemente, novas relações de poder e de concorrência são constatadas e novos fatores de incompatibilidade entre os atores sociais e as unidades estatais passaram a ser colocados à prova a cada dia, fazendo com que o direito também se adeque aos novos acontecimentos, pois o direito é um fato ou fenômeno social; não existe se não na sociedade e não pode ser concebido fora dela ${ }^{7}$.

Ainda em 1956 Jessup $^{8}$, em seu compilado de ideias denominado Transnational Law, analisou os problemas da então comunidade mundial interrelacionada, que principia com o indivíduo e alcançava a sociedade de Estados, por considerar que a comunidade mundial estava criando laços cada vez mais complexos e que a expressão direito internacional estaria superada e já não atendia às exigências conceituais da nova época que se desenhava.

É de se ressaltar que a transnacionalidade não pode ser confundida com a globalização, mas também desta não pode ser dissociada. Trata-se de fenômenos interligados em que a primeira nasce no contexto da segunda. Acertada é a exposição de Baumann ao entender que "Con transnazionalismo entendiamo tutti i vincoli che attraversano i confini dello stato-nazione; con globalizzazione vogliamo significare che il mondo si è trasformato in un [...] 'villaggio globale' - o forse una città globale con quartieri molto differenti”'. Significa, portanto, que a transnacionalidade emerge da limitação da internacionalização ${ }^{10}$ e é verificada a partir da efetivação da globalização.

Para Arnaud, falar de globalização é mais do que simplesmente falar de internacionalização. A realidade que se passa com a nação nesse processo de intercâmbios pode ser chamada de transnacionalização, embora essas diferenciações possam ser tênues ${ }^{11}$.

Deste modo, a transnacionalidade é concebida como "aquilo que atravessa o nacional, que perpassa o Estado, que está além da concepção soberana do Estado e, por consequência, traz consigo, inclusive, a ausência da dicotomia público e privado"12. Além disso, outras características são evidenciadas ao analisar tal fenômeno. 
A primeira delas seria o conjunto de transformações relativas aos espaços territoriais nacionais que antes eram pensados isoladamente, ou em conjunto com outros somente internacionalmente. Tradicionalmente, o direito internacional fundava-se no princípio da territorialidade, e o respeito a esse princípio era, em regra, suficiente para assegurar um funcionamento satisfatório das relações internacionais ${ }^{13}$. Hoje, porém, as relações transfronteiriças exigem grau maior de sofisticação do direito, e se apresentam como manifestações da transnacionalidade, podendo-se citar como exemplos os crimes transnacionais, o direito desportivo, o direito ambiental e a sustentabilidade, as corporações transnacionais, as migrações transnacionais etc ${ }^{14}$.

As alterações propiciadas pela globalização também deram origem a novas situações, antes não vivenciadas nem pensadas devido à sua abrangência e característica de novo, atualmente circundadas por articulações que diferem do espaço real e não mais atendem a espaços territoriais pré-definidos. Segundo Arnaud $^{15}$, a globalização, por assim dizer, é uma tomada de consciência de que muitos problemas nesse fim de século, não podem ser mais tratados através da simples referência aos Estados sem uma referência aos vínculos que passaram a unir as diferentes partes do globo terrestre.

Eis a razão pela qual a transnacionalidade atravessa diferentes níveis de integração, tornando difícil relacioná-la a algum território circunscrito. Esta é a característica da desterritorialização citada por Stelzer ${ }^{16}$ sob o argumento de que "O território transnacional não é nem um nem outro e é um e outro, posto que se situada na fronteira transpassada, na borda permeável do Estado" ${ }^{17}$, flutuando sobre os Estados e fronteiras.

Ambrosini ${ }^{18}$ menciona que a transnacionalidade pode ser verificada a partir da implementação das premissas de facilitação dos transportes e da comunicação, da alteração do pertencimento a determinado grupo social ou político - ou seja, a partir dos eventos produzidos pela globalização - em que se tornou possível a vivência de uma vida dupla para muitas pessoas: por meio de contatos que atravessam e permeiam as fronteiras nacionais, que desconhecem nacionalidades ou normas pré-definidas e pugnam por um reconhecimento até então não pensado.

Por esta razão, os acontecimentos de hoje são transnacionais porque ocorrem de forma recorrente para além das fronteiras nacionais e requerem um compromisso regular e significativo de todos os participantes. Ferrajoli ${ }^{19}$ entende que a globalização é responsável pela crise do direito em um duplo sentido e a transnacionalidade apresenta-se como o sentido objetivo desta crise, por afetar o Estado na sua esfera institucional e atribuir-lhe uma considerável falta de importância.

Assim, à medida que a globalização desenvolve sua dinâmica por meio das dimensões por ela criadas, cresce a necessidade dos envolvidos de se localizarem em novos cenários e de encontrarem maneiras de contrabalançar as 
novas tendências. Isto demonstra que a transnacionalidade possui ligação com a globalização e o sistema-mundo, mas a sua própria particularidade reside no fato de apontar para uma questão central: a relação entre territórios e os diferentes arranjos que orientam as maneiras como as pessoas representam pertencimento a unidades socioculturais, políticas e econômicas. Isto é o que Ribeiro ${ }^{20}$ denomina como modos de representar pertencimento a unidades socioculturais, políticoeconômicas.

Discorrer sobre a transnacionalidade impõe uma tarefa muitas vezes árdua ante a necessidade de modificar as clássicas concepções já consolidadas com vistas a destacar as relações transpassantes que afetam direta ou indiretamente a todos, a fim de ordenar um claro senso de responsabilidade com relação aos efeitos de ações políticas e econômicas em um mundo globalizado ${ }^{21}$.

Seguindo esta ordem, Piffer ${ }^{22}$ apresenta alguns dos principais traços característicos do fenômeno da transnacionalidade: 1) As ocorrências transnacionais tendem a se apresentar como relações horizontais, pois horizontal é a linha que conecta e estabelece relações de todos com todos, rasgando as fronteiras nacionais e estabelecendo ligações por onde passa, não possuindo um único ponto de partida nem mesmo um ponto de chegada; 2) As relações hoje estabelecidas perderam o caráter de excepcionalidade ou ocasionalidade; o que antes não afetava o sentimento de pertencimento ou as coordenadas culturais e institucionais de um determinado grupo ou país hoje demonstra sua característica transnacional por ser uma necessidade de inter-relação incentivada de vários modos; 3) Diante da desterritorialização houve o rompimento - de fato - da unidade estatal, marcado por novas relações de poder e competitividade, gerando conflitos e jogos de interesse sem origem definida; 4) Verifica-se o enfraquecimento dos sistemas de controle e proteção social diante das redes de legalidade estabelecidas, em que regras e normas parecem ser desafiadas por outras potenciais ou atuais, localizadas em território diversos e ditadas por corporações transnacionais sob os ditames da globalização; 5) Estabelecem-se redes de legalidades complementares ou antagônicas que são típicas das relações transnacionais e dão origem a constantes mutações ou transgressões das regras pré-estabelecidas, em que o Estado nacional atua como mero coadjuvante por meio do seu aparato estatal restrito às fronteiras nacionais ou a prévios acordos internacionais que possuem a característica de verticalidade e não horizontalidade.

Diante destas características, verifica-se que a transnacionalidade questiona a todo o momento a lógica e eficácia dos modos pré-existentes de controle e representação na esfera econômica, social, cultural, política e jurídica. E a sociedade mundial abordada no início deste estudo, não mais padece das balizas - povo, território e jurisdição - impostas pelas categorias estatais clássicas, atreladas às engessadas teorias monistas e dualistas. 


\section{A NECESSIDADE DE SUPERAÇÃO DAS TEORIAS MONISTA E DUALISTA}

São duas as teorias que regulam as relações entre o direito interno dos Estados e o direito internacional: a teoria monista e a teoria dualista.

A primeira prega que tanto o direito interno quanto o internacional, constituem o mesmo sistema jurídico, ou seja, que existe apenas uma única ordem jurídica que dá origem às normas internacionais e nacionais, tendo o reconhecimento mútuo nas duas esferas sem qualquer burocracia. Seguindo esta linha de pensamento, convém transcrever as palavras de Kelsen ${ }^{23}$ :

Se o Direito internacional e o Direito estadual formam um sistema unitário, então a relação entre eles tem de ajustar-se a uma das duas formas expostas. O Direito internacional tem de ser concebido, ou como uma ordem jurídica delegada pela ordem jurídica estadual e, por conseguinte, como incorporada nesta, ou como uma ordem jurídica total que delega nas ordens jurídicas estaduais, supraordenada a estas e abrangendo-as a todas como ordens jurídicas parciais. Ambas estas interpretações da relação que intercede entre o Direito internacional e o Direito estadual representam uma construção monista. A primeira significa o primado da ordem jurídica de cada Estado, a segunda traduz o primado da ordem jurídica internacional.

Por sua vez, o dualismo defende haver distinção entre o ordenamento jurídico interno e o internacional, sendo a ordem jurídica interna compreendida pela Constituição e demais normas específicas de cada Estado e reconhecidas no seu âmbito doméstico, enquanto a ordem internacional - regida por tratados, acordos e convenções - seria reconhecida apenas na esfera internacional coordenando as relações entre soberanos, devendo ser internalizada para ter validade jurídica no Estado signatário.

A este respeito, Kelsen entende que esta discussão teórica serve somente para demonstrar o afastamento de uma compreensão jurídica integradora, defendendo que:

Na medida em que fosse este o significado de uma teoria que crê ter de aceitar a existência de conflitos insolúveis entre Direito internacional e Direito estadual e considera o Direito internacional, não como Direito, mas apenas como uma espécie de Moral internacional, nada haveria a opor-lhe do ponto de vista da lógica. Mas a generalidade dos representantes da teoria dualista vê-se forçada a considerar o Direito internacional e o Direito estadual como ordens jurídicas com vigência simultânea que são independentes uma da outra nessa 
sua vigência e podem entrar em conflito uma com a outra. Esta doutrina é insustentável ${ }^{24}$.

Aliado a esta discussão, outro percalço afeta as teorias ora apresentadas: a sua superação frente à emergência da perspectiva jurídica da transnacionalidade, aqui denominada como direito transnacional. Sanz $z^{25}$ sugere que estamos diante de um colapso da teoria monista, o que nos obriga a revisar conceitos-chave das construções jus teóricas ainda em voga, e melhor sorte não socorre o dualismo.

Vale destacar que as reflexões acerca de um embrionário direito transnacional já vêm se desenvolvendo desde o século passado, quando, ainda em 1976, Vagts e Steiner passaram a refletir sobre problemas jurídicos no âmbito transnacional, por meio da obra intitulada Transnational legal problems ${ }^{26}$. Os autores, à época, realizaram complexos estudos sobre direito internacional, conflito de leis no tempo e no espaço, direito comparado, jurisprudência e negócios e transações transnacionais, adotando o posicionamento de Jessup ${ }^{27}$ para analisar tais situações.

Destaca-se para o fato de que nessa obra, os autores identificam as características e o alcance dos problemas jurídicos transnacionais nos sistemas jurídicos domésticos e internacionais, utilizando exemplos como a manutenção da paz e o controle da violência relacionados ao Vietnã, os conflitos existentes entre o Congresso e o Executivo dos Estados Unidos quanto às relações e aos acordos internacionais, e a discussão sobre os direitos humanos e sua abrangência transnacional ${ }^{28}$.E conforme dito, tudo isso ainda na década de 1980.

Especificamente em 1986, Vagts $^{29}$ abordou a matéria na sua obra Transnational Business Problems, examinando os comportamentos dos atores envolvidos nas relações transnacionais, surgindo, neste momento, uma análise que vai além do direito, ao observar a forma como este próprio surge a partir das relações entre os sujeitos envolvidos.

Para o autor, seriam três os elementos caracterizadores do Direito Transnacional: 1) assuntos que transcendem as fronteiras nacionais; 2) assuntos que não comportam uma clara distinção entre Direito Público e Privado; e 3) assuntos que comportam fontes abertas e flexíveis, como o soft law ${ }^{30}$.

Há mais de uma década, Berman ${ }^{31}$ também expôs que a ênfase tradicional do direito internacional no Estado tem sido questionada há tempos, e o foco mais recente se volta ao direito transnacional, vez que redes governamentais e não-governamentais, influência judicial e cooperação transfronteiriça, ainda parecem insuficientes para descrever as complexidades do direito em uma era de globalização.

Desse modo, o direito transnacional, perquire uma dupla superação ${ }^{32}$.

Primeiramente da teoria monista, no que diz respeito às suas características estatal, quanto à suposição da autossuficiência das ordens jurídicas estatais e 
a negação de qualquer outra ordem jurídica, e internacionalista, cujo Estado entrega toda a legitimação do seu poder normativo ao direito internacional. Em ambas perspectivas, são totalmente subestimadas as complexas redes de relações jurídicas que operam na esfera transnacional.

E também quanto à superação do dualismo, pois a ideia de que a ordem interna e internacional devem ser construídas como ordens reciprocamente independentes, mostra-se inadequada ante o fato de que o direito transnacional dá sobremaneira atenção para as relações mútuas entre ordens jurídicas e atores variados, em um constante processo de integração e coordenação.

Significa, portanto, que as lentes do direito, tanto pela ótica monista quanto pela dualista, não são mais suficientes para observar as complexas redes de relações que se afetam mutuamente, nem mesmo para fornecer-lhes respostas adequadas. Para perquirir tal mudança, precisamos nos desprender da imagem dos Estados soberanos e independentes, pois a maioria das ordens jurídicas e não jurídicas que hoje coexistem comportam diversos tipos de relações que se integram e complementam, e não podem ser pressagiadas no campo teórico.

Nesse diapasão, o assunto que ora pretende-se abordar visa defender que o direito transnacional pode subsidiar as discussões e soluções jurídicas, vez que as teorias clássicas não mais "saciam a sede jurídica" da sociedade atual. Cabe ao direito transnacional, portanto, a árdua tarefa de refomular conceitos básicos da ciência jurídica com vistas a consolidar a formação de um pluralismo jurídico forte e demonstrar como nossas concepções tradicionais do direito devem ser repensadas frente à realidade transnacional contemporânea. Este será o assunto abordado na sequência.

\section{A ORDEM JURÍDICA TRANSNACIONAL E A CONSOLIDAÇÃO DE UM PLURALISMO JURÍDICO TRANSNACIONAL}

Partindo do pressuposto de que a conexão entre direito e território estatal há tempos sofre uma considerável transformação, é fato que os limites geográficos dos Estados e as regras formadoras do direito nacional e internacional não mais definem a máxima extensão de incidência das normas jurídicas. O Estado já não é mais o único ator, nem mesmo o mais importante a estabelecer ordens jurídicas.

Conforme salienta Teubner ${ }^{33}$, a emergência de ordens supra e transnacionais, públicas e privadas, traz ao sistema jurídico elementos de complexidade fazendo com que os pressupostos já pacificados da modernidade devam ser necessariamente relidos. Enquanto a teoria jurídica continua focada nos sistemas jurídicos nacionais, a prática vai muito mais além, transpassando fronteiras e escrevendo sua história por linhas complexas de uma realidade jurídica que se desenvolve sem a presença da figura estatal. 
Scott ${ }^{34}$ ressalta que não há que se falar da exclusão desta figura, mas sim de categorias mutuamente inclusivas que se mesclam com um direito que não é nem nacional, nem internacional - um híbrido entre direito nacional e internacional, segundo $\mathrm{Koh}^{35}$-, nem público, nem privado, mas que pode ser nacional e internacional, público e também privado.

Como explicita Dolinger, "os doutrinadores, tanto os de direito internacional público quanto os de direito internacional privado, relacionam a questão do conflito entre fontes internas e internacionais às clássicas doutrinas do monismo e do dualismo, cada qual propondo uma solução diferente ${ }^{36}$. No entanto,

La diversidad jurídica de nuestros días obliga a cada orden jurídico a afrontar la interacción y apertura a otras realidades jurídicas. Una aproximación transnacional, a diferencia del pluralismo jurídico fuerte, tiene la pretensión de evitar el aislamiento de cada orden jurídico respecto de la realidad jurídica circundante y favorecer un proceso de progresiva convergencia normativa que permita encauzar los conflictos sociales que traspasan las fronteras en procesos jurídicos ${ }^{37}$.

Defende-se, portanto, a necessidade de superação de um pluralismo limitado à comparação e convergência entre sistemas jurídicos distintos. A principal característica diferenciadora do pluralismo jurídico (chamado pelo autor de pluralismo jurídico forte) e do direito transnacional, se refere à impossibilidade do primeiro realizar atos de convergência, coordenação e integração entre ordens jurídicas e não jurídicas. Para que a teoria do pluralismo jurídico possa ser utilizada em demandas transnacionais, deveria sofrer uma reformulação de suas bases, como explica Teubner ${ }^{38}$. O autor demonstra que, em contraposição à visão de Kant (para o qual a globalização do direito só é possível por meio da codificação da política internacional), faz-se necessário fundamentar o pluralismo não mais em grupos e comunidades, mas, sim, em discursos e redes de comunicação.

As lentes pelas quais se deve enxergar o direito não seriam mais aquelas que refletem a existência de uma ordem única de atores soberanos, mas sim a de uma constelação de sistemas jurídicos inter-relacionados. Somente por meio da teoria do pluralismo jurídico transnacional torna-se possível conceber o direito transnacional ${ }^{39}$. E este, por sua vez, muito além de institucionalizar garantias de direitos reconhecidos formalmente, possui o atributo de fomentar instrumentos de aperfeiçoamento constante dos conteúdos materiais pensados em uma ordem plural, com uma visão que deriva de uma realidade em movimento e constante integração, fundada em uma reflexão crítica que afaste o que Tuori ${ }^{40}$ chama de pluralismo radical.

Além disso, existe uma pluralidade de normas que não necessariamente estão centralizadas ${ }^{41}$, nem mesmo respeitam a determinada hierarquia, conforme estamos comumente acostumados. As relações entre regimes jurídicos diversos 
são muito variadas, podendo se convergir, cooperar, assimilar, subordinar, competir e integrar ${ }^{42}$.

Chama-se atenção para o fato de que nessa nova consciência jurídica surgem novos atores, que se relacionam e se comunicam formando as referidas redes especializadas na esfera transnacional. Assim, os Estados-nação são forçados a se comportarem como coatores, sem divisão hierárquica de papeis.

Em um mundo sem soberania plena, os Estados são obrigados a se comportar como atores, entre os demais. O Estado, soberano (até certo ponto) no seu próprio território, perde toda a soberania (apesar do que diz o direito internacional público) assim que atravessa fronteiras e deve comprometer-se com outras forças ${ }^{43}$. Estas forças são de outros Estados, é claro, mas também de outros tipos de atores da sociedade do mundo, como as organizações internacionais e as organizações não-governamentais, ou empresas de transição e suas redes, além de outras formas de organização social que participam do fenômeno transnacional.

A aceitação da existência de um pluralismo jurídico transnacional se consolidou na esfera econômica, em que a realidade dos mercados mundiais impuseram uma nova ordem jurídica transnacional, sendo insustentável negar a força jurídica dessas novas regulamentações que coadunam com as reflexões de Teubner, no sentido de que aquilo que antes era um não direito, agora é um Direito sem o Estado, se apresentando como um direito mundial autônomo ${ }^{44}$. Isto porque a maioria das transações comerciais hodiernas não se submetem às leis nacionais ou internacionais. Como afirma Arnaud ${ }^{45}$, na verdade as corporações pouco se preocupam com essas normas. Em tom de crítica, Beck complementa que as empresas transnacionais fazem parte de "Um capitalismo transnacional que não arrecada impostos e destrói postos de trabalho [...]".

Para Zumbansen ${ }^{46}$, o direito transnacional engloba muito mais do que meramente transações transfronteiriças de direito privado envolvendo intervenientes não estatais e redes reguladoras. Em vez disso, ele abarca esses relacionamentos entre atores estatais e não-estatais através dos limites do Estado que ficam aquém de conduzir a actos jurídicos internacionais oficiais, tais como tratados ou convenções.

No entanto, os reflexos jurídicos das relações transnacionais não se cingem às questões econômicas. Contenciosos envolvendo direitos humanos, questões ambientais, atos de governança transnacional, organizações sociais transnacionais, relações trabalhistas, relações familiares, contratos públicos ou privados e tantas outras searas - jurídicas e não jurídicas - compõem o atual pluralismo jurídico transnacional. São elas que constroem e consolidam as constatações de uma sociedade em constante mutação.

Cabe portanto, aos operadores do direito, tomar consciência de que o direito transnacional precisa ser assimilado, estudado e discutido. Este é um débito que precisa ser quitado com a sociedade mundial. 


\section{CONSIDERAÇÕES FINAIS}

Sociedade mundial, transnacionalidade, direito transnacional e pluralismo jurídico transnacional foram as principais categorias abordadas neste estudo. $\mathrm{O}$ intento principal foi o de demonstrar que a aceitação, e a consequente compreensão do direito transnacional, passa pela ruptura categórica com elementos clássicos da ciência jurídica.

A verificação da transnacionalidade como fenômeno e o direito transnacional como sua dimensão jurídica, ante a característica de ausência de subordinação a um espaço jurídico pré-estabelecido, se constitui como importante alicerce da consolidação de um pluralismo jurídico que muito se difere do pluralismo clássico: o pluralismo jurídico transnacional.

A diversidade jurídica que hoje se constata nos obriga a afrontar a convergência, coordenação e integração entre sistemas jurídicos e não jurídicos, afastando qualquer tentativa de manter as ordens jurídicas apartadas ante o argumento arcaico de centralização das decisões, ações e procedimentos, unicamente no Estado nacional.

Mais do que suplantar as teorias monistas e dualistas, mostra-se imprescindível afrontar qualquer tentativa de pluralismo adstrito a atos jurídicos de comparação e convergência. A teoria do direito transnacional permite, portanto, elevar o desafio que enfrentam fenômenos jurídicos que transcendem fronteiras do Estado, superando modelos categorizados em local, internacional, supranacional ou global, e enfatizando a interdependência entre eles.

\section{NOTAS}

1 BECK, Ulrich. O que é Globalização? Equívocos do globalismo, respostas à Globalização. São Paulo: Paz e Terra, 1999. p. 18

2 BECK, Ulrich. O que é Globalização? Equívocos do globalismo, respostas à Globalização. p. 29.

3 BECK, Ulrich. O que é Globalização? Equívocos do globalismo, respostas à Globalização. p. 29-30.

4 HABERMAS, Jürgen. A constelação pós-nacional: ensaios políticos. Tradução de Márcio Seligmann Silva. São Paulo: Littera Mundi, 2001. Título original: Die postnationale Konstellation: Politische Essays. p. 74

5 Para Wallerstein "Un sistema-mondo non è il sistema del mondo, ma un sistema che è un mondo e che può essere e molto spesso è stato, localizzato in un'area che non copre l'intera superficie del globo". WALLERSTEIN, Immanuel. Compreendere Il mondo. Introduzione all'analisi dei sistemimondo. Trieste: Saterios, 2006. p. 143.

6 MORAIS, Jose Luis Bolzan de. As crises do Estado e da Constituição e a transformação espaçotemporal dos direitos humanos. 2. ed. rev. ampl. Porto ALegre: Livraria do Advogado, 2011. p. 12.

7 REALE, Miguel Reale. Lições Preliminares de Direito. 27 ed. São Paulo: Saraiva, 2002.

8 Para Jessup, o Direito Transnacional inclui todo o direito que regula ações ou eventos que transcendem fronteiras nacionais. Tanto o Direito Internacional Público quanto o Privado estão 
incluídos, assim como estão outras regras, que não se encaixam perfeitamente nessas categorias usuais. A citação de Jessup serve mais como ponto de reflexão, pois o que ele verificando era o início da globalização e consentindo sobre o surgimento de um complexo emaranhado de relações à margem da capacidade regulatória e de intervenção do Estado Moderno. JESSUP, Philip C. Direito transnacional. Tradução de Carlos Ramires Pinheiro da Silva. São Paulo: Fundo de Cultura, 1956.

9 “BAUMANN, Gerd. L'enigma multiculturale. Bologna: Mulino, 2003. p. 160.

10 [...] a expressão latina trans significaria algo que vai "além de" ou "para além de", a fim de evidenciar a superação de um lócus determinado, que indicaria que são perpassadas diversas categorias unitárias, num constante fenômeno de desconstrução e construção de significados. Diversamente da expressão inter, a qual sugere a ideia de uma relação de diferença ou apropriação de significados relacionados, o prefixo trans denota a emergência de um novo significado construído reflexivamente a partir da transferência e transformação dos espaços nacionais, inclusive de modo que não seja pensado internacionalmente, e sim no surgimento de algo novo, de um espaço transpassante, que já não se encaixa nas velhas categorias modernas. CRUZ, P.; BODNAR, Z. A transnacionalidade e a emergência do Estado e do direito transnacionais. In: CRUZ, P.M.; STELZER, J. (Orgs.). Direito e Transnacionalidade. Curitiba: Juruá, 2009. p. 58.

11 ARNAUD André-Jean. O Direito entre Modernidade e globalização: lições de filosofia do direito e do Estado. Rio de Janeiro: Renovar, 1999, p. 11.

12 STELZER, Joana. O fenômeno da transnacionalização da dimensão jurídica. In: CRUZ, Paulo Márcio; STELZER, Joana (Orgs.). Direito e Transnacionalidade. p. 24-25.

13 MATIAS, Eduardo Felipe Pérez. A humanidade e suas fronteiras: do Estado soberano à Sociedade global. São Paulo: Paz e Terra, 2005. p. 345.

14 A este respeito, sugere-se a leitura de: PIFFER, Carla; CRUZ, Paulo Márcio. Manifestações do direito transnacional e da transnacionalidade. p. 8-27, In: PIFFER, Carla; BALDAN, Guilherme Reibeito; CRUZ, Paulo Márcio (Orgs.) Transnacionalidade e sustentabilidade: dificuldades e possibilidades em um mundo em transformação. Porto Velho: Emeron, 2018.

15 ARNAUD André-Jean. O Direito entre Modernidade e globalização: lições de filosofia do direito e do Estado. p. 13.

16 STELZER, Joana. O fenômeno da transnacionalização da dimensão jurídica. In: CRUZ, Paulo Márcio; STELZER, Joana (Orgs.). Direito e Transnacionalidade. p. 25.

17 STELZER, Joana. O fenômeno da transnacionalização da dimensão jurídica. In: CRUZ, Paulo Márcio; STELZER, Joana (Orgs.). Direito e Transnacionalidade. p. 25.

18 AMBROSINI, Maurizio. Un'altra globalizzazione: la sfida delle migrazioni transnazionali. Bologna: Il Mulino, 2009. p. 11-38.

19 Segundo o autor, "Il tratto caratteristico di quella che chiamiamo 'globalizzazione' è dunque la crisi del diritto in duplice senso, l'uno oggettivo e istituzionale, l'altro, per così dire soggetivo e Culturale: a) come crescente incapacità regolativa del diritto, che si esprime nelle sue vistose e incontrollate violazioni da parti di tutti i poteri, pubblici e privati, nel vuoto di regole idonee a disciplinarne le nuove dimensioni transnazionali; b) come squalificazione, insofferenza e rifiuto del diritto, che si esprime nell'idea che i supremi poteri politici, magari perchè legittimati democraticamente, non siano sottoposti a regole, né di diritto internazionale né di diritto costituzionale, e che parimenti il mercato non possa, ma debba fare a meno di regole e limiti, considerati come inutili impacci alle sua capacità di autoregolazione e di promozione dello sviluppo". FERRAJOLI, Luigi. Diritti fondamentali: un dibattito teorico. A cura di Ermanno Vitale. 3. ed. Roma: Editori Laterza, 2008. p. 353.

20 RIBEIRO, Gustavo Lins. A condição da transnacionalidade. Série antropologia, 1997. Disponível em: <http://pt.scribd.com/doc/19503341/A-Transnacionalidade>. Acesso em: 02 ago. 2018. 
21 CRUZ, Paulo Márcio; PIFFER, Carla. Migrações Transnacionais, p. 126. In: OLIVEIRA NETO, Francisco José Rodrigues de; ABREU, Pedro Manoel; ZANON JUNIOR, Orlando Luiz Zanon Junior (Orgs.). Direito, Democracia e Constitucionalismo. Itajaí: UNIVALI, 2018.

22 PIFFER, Carla. Transnacionalidade e Imigração: a possibilidade de efetivação dos Direitos Humanos dos Transmigrantes diante de Decisões de Regresso na Itália e na União Europeia. Tese (Doutorado em Ciência Jurídica), Universidade do Vale do Itajaí - UNIVALI, Itajaí, 2014. Disponível em: <http://siaibib01.univali.br/pdf/Carla\%20Piffer.pdf>. Acesso em: 20 mar 2019.

23 KELSEN, Hans. Teoria pura do direito. Tradução de João Baptista Machado. São Paulo: Martins Fontes, 1999. p. 233.

24 KELSEN, Hans. Teoria pura do direito. p. 231.

25 SANZ, Mario Ruiz. Sociedades multiculturales y sistemas jurídicos: intersecciones y confrontaciones. Derechos y libertades, 32, 2015, p. 79-105. Doi: 10.14679/1003. p. 99.

26 STEINER, Henry J.; VAGTS, Detlev F.; KOH, Harold H. Transnational Legal Problems: Materials and Text. 4. ed. New York: The Foundation Press, 1994.

27 Philip Jessup foi o pioneiro a escrever acerca da transnacionalidade e sua dimensão jurídica. Ao vivenciar um momento histórico de aprimoramento e intensificação das relações entre Estados, Jessup externava a dificuldade que envolvia a análise dos problemas da comunidade mundial e do direito que a regulava, ante a inexistência de uma expressão apropriada para designar as normas em questão, vez que o Direito Internacional não se mostraria apropriado para tal. Por essa razão, o autor passou a usar a expressão Direito Transnacional para incluir todas as normas que regulam atos ou fatos que transcendem as fronteiras nacionais, vez que, para ele, as situações transnacionais poderiam envolver indivíduos, empresas, Estados, organizações de Estados ou qualquer outros grupos. JESSUP, Philip C. Direito transnacional. Tradução de Carlos Ramires Pinheiro da Silva. São Paulo: Fundo de Cultura, 1956. p. 11.

28 Vagts, no ano de 1986, continuou a abordar a temática em sua obra intitulada Transnational business problems, na qual expõe os três elementos que caracterizam o direito transnacional: os assuntos que transcendem fronteiras nacionais; os assuntos que não comportam uma clara distinção entre direito público e direito privado; e os assuntos mencionados no artigo 38 da Corte Internacional de Justiça, além de outros que possuam fontes abertas e flexíveis, como seria o caso do soft law.

29 VAGTS, Detlev F. Transnational business problems. New York: The Fundation Press, 1986.

30 CRUZ, Paulo Marcio; PIFFER, Carla. Transnacionalidade, migrações transnacionais e os direitos dos trabalhadores migrantes. Revista do Direito, Santa Cruz do Sul, v. 3, n. 53, p. 51-66, set./ dez. 2017. p. 53.

31 BERMAN, Paul Schiff, From International Law to Law and Globalization. University of Connecticut School of Law Articles and Working Papers. Paper 23, 2005. p. 485. Disponível em: $<$ htp://lsr.nellco.org/uconn_wps/23>. Acesso em: 01 mar 2019.

32 GUASTINI, Riccardo. La sintaxis del derecho. Madrid: Marcial Pons, 2016. p. 329.

33 TEUBNER,Gunther. Fragmented Foundations: Societal Constitutionalism Beyond the Nation State. In: DOBNER, Petra. LOUGHLIN,Martin.(Org.). TheTwilightof Constitutionalism? Oxford:Oxford University Press, 2010. p. 331-332.

34 SCOTT, C. Transnational Law as Proto-Concept: Three Conceptions. German Law Journal, 10(7), 859-876. DOI: 10.2139/ssrn.1488245. p. 873.

$35 \mathrm{KOH}$, Harold H. Why transnational law matters. Faculty Scholarship Series. Paper 1793. Yale Law School Legal Scholarship Repository. HeinOnline - 24 Penn St. Int'l L. Rev. 752, 2005-2006. Disponível em: <http://digitalcommons.law.yale.edu/fss_papers/1793>. Acesso em: 18 fev. 2019. 
36 DOLINGER, Jacob. Direito Internacional Privado, Rio de Janeiro: Renovar, 1994. p. 102:

37 MANSILLA, Isabel Turégano. Derecho transnacional o la necesidad de superar el monismo y el dualismo en la teoría jurídica. Derecho PUCP. n. 79, 2017. p. 223-265. p. 225.

38 TEUBNER, Gunther. A Bukowina Global sobre a Emergência de um Pluralismo Jurídico Transnacional. Impulso, Piracicaba, v. 14, n. 33, p. 9-32, jan./abr. 2003. p. 17.

39 FRYDMAN, Benoit. A pragmatic approach to global law. 2013. Disponível em: <http://ssrn. com/abstract=2312504>. Acesso em: 13 jan. 2019. p. 04 .

40 TUORI, K. Transnational Law. On Legal Hybrids and Perspectivism, p. 11-57. In: MADURO, M.; TUORI, K.; SANKARI, S. (Orgs) Transnational Law. Rethinking European Law and Legal Thinking. Cambridge: Cambridge University PressUORI, 2014. p. 41

41 Como exemplo, cita-se a lex mercatória. Para Teubner ela rompe com dois tabus: o primeiro de que sua afirmação só se dá através de disposições jusprivatistas (contratos e fusões); e o segundo, reivindicando validade entre os Estados-nações e até além das relações "inter-nacionais", formandose espontaneamente no plano transnacional, sem a autoridade do Estado, sem a sua capacidade de impor sanções, sem o seu controle político e sem a legitimidade de um processo democrático. TEUBNER, Gunther. A Bukowina Global sobre a Emergência de um Pluralismo Jurídico Transnacional. Impulso, Piracicaba, v. 14, n. 33, p. 9-32, jan./abr. 2003. p. 17.

42 MANSILLA, Isabel Turégano. Derecho transnacional o la necesidad de superar el monismo y el dualismo en la teoría jurídica. Derecho PUCP. n. 79, 2017. p. 223-265. p. 232.

43 FRYDMAN, Benoit. A pragmatic approach to global law. 2013. Disponível em: <http://ssrn. com/abstract=2312504>. Acesso em: 13 jan. 2019. p. 06.

44 TEUBNER, Gunther. Os múltiplos corpos do rei: a autodestruição da hierarquia do direito. In: FILOSOFIA do direito e direito econômico que diálogo? Lisboa: Instituto Piaget, 1999. p. 343

45 ARNAUD André-Jean. O Direito entre Modernidade e globalização: lições de filosofia do direito e do Estado. p. 22-27.

46 ZUMBANSEN, Peer. Transnational Law. Comparative Research in Law \& Political Economy. Research Paper No. 9/2008. Disponível em: <htp://digitalcommons.osgoode.yorku.ca/clpe/181>. Acesso em: 11 mar. 2019. p.739.

\section{REFERÊNCIAS}

AMBROSINI, Maurizio. Un'altra globalizzazione: la sfida delle migrazioni transnazionali. Bologna: Il Mulino, 2009.

ARNAUD André-Jean. O Direito entre Modernidade e globalização: lições de filosofia do direito e do Estado. Rio de Janeiro: Renovar, 1999.

BAUMANN, Gerd. L'enigma multiculturale. Bologna: Mulino, 2003.

BECK, Ulrich. O que é Globalização? Equívocos do globalismo, respostas à Globalização. São Paulo: Paz e Terra, 1999.

BERMAN, Paul Schiff, From International Law to Law and Globalization. University of Connecticut School of Law Articles and Working Papers. Paper 23, 2005. p. 485. Disponível em: <htp://lsr.nellco.org/uconn_wps/23>. Acesso em: 01 mar 2019. 
CRUZ, Paulo Márcio.; BODNAR, Zenildo. A transnacionalidade e a emergência do Estado e do direito transnacionais. In: CRUZ, P.M.; STELZER, J. (Orgs.). Direito e Transnacionalidade. Curitiba: Juruá, 2009.

; PIFFER, Carla. Transnacionalidade, migrações transnacionais e os direitos dos trabalhadores migrantes. Revista do Direito, Santa Cruz do Sul, v. 3, n. 53, p. 51-66, set./ dez. 2017.

; PIFFER, Carla. Migrações Transnacionais. In: OLIVEIRA NETO, Francisco José Rodrigues de; ABREU, Pedro Manoel; ZANON JUNIOR, Orlando Luiz Zanon Junior (Orgs.). Direito, Democracia e Constitucionalismo. Itajaí: UNIVALI, 2018.

DOLINGER, Jacob. Direito Internacional Privado, Rio de Janeiro: Renovar, 1994.

FERRAJOLI, Luigi. Diritti fondamentali: un dibattito teorico. A cura di Ermanno Vitale. 3. ed. Roma: Editori Laterza, 2008.

FRYDMAN, Benoit. A pragmatic approach to global law. 2013. Disponível em: <http:// ssrn.com/abstract=2312504>. Acesso em: 13 jan. 2019.

GUASTINI, Riccardo. La sintaxis del derecho. Madrid: Marcial Pons, 2016.

HABERMAS, Jürgen. A constelação pós-nacional: ensaios políticos. Tradução de Márcio Seligmann Silva. São Paulo: Littera Mundi, 2001. Título original: Die postnationale Konstellation: Politische Essays.

JESSUP, Philip C. Direito transnacional. Tradução de Carlos Ramires Pinheiro da Silva. São Paulo: Fundo de Cultura, 1956.

KELSEN, Hans. Teoria pura do direito. Tradução de João Baptista Machado. São Paulo: Martins Fontes, 1999.

KOH, Harold H. Why transnational law matters. Faculty Scholarship Series. Paper 1793. Yale Law School Legal Scholarship Repository. HeinOnline - 24 Penn St. Int'l L. Rev. 752, 2005-2006. Disponível em: <http://digitalcommons.law.yale.edu/fss_papers/1793>. Acesso em: 18 fev. 2019.

MANSILLA, Isabel Turégano. Derecho transnacional o la necesidad de superar el monismo y el dualismo en la teoría jurídica. Derecho PUCP. n. 79, 2017. p. 223-265.

MATIAS, Eduardo Felipe Pérez. A humanidade e suas fronteiras: do Estado soberano à Sociedade global. São Paulo: Paz e Terra, 2005.

MORAIS, Jose Luis Bolzan de. As crises do Estado e da Constituição e a transformação espaço-temporal dos direitos humanos. 2. ed. rev. ampl. Porto Alegre: Livraria do Advogado, 2011.

PIFFER, Carla. Transnacionalidade e Imigração: a possibilidade de efetivação dos Direitos Humanos dos Transmigrantes diante de Decisões de Regresso na Itália e na União Europeia. Tese (Doutorado em Ciência Jurídica), Universidade do Vale do Itajaí UNIVALI, Itajaí, 2014. Disponível em: <http://siaibib01.univali.br/pdf/Carla\%20Piffer. pdf>. Acesso em: 20 mar 2019. 
; CRUZ, Paulo Márcio. Manifestações do direito transnacional e da transnacionalidade. p. 8-27, In: PIFFER, Carla; BALDAN, Guilherme Reibeito; CRUZ, Paulo Márcio (Orgs.) Transnacionalidade e sustentabilidade: dificuldades e possibilidades em um mundo em transformação. Porto Velho: Emeron, 2018.

REALE, Miguel Reale. Lições Preliminares de Direito. 27 ed. São Paulo: Saraiva, 2002.

RIBEIRO, Gustavo Lins. A condição da transnacionalidade. Série antropologia, 1997. Disponível em: <http://pt.scribd.com/doc/19503341/A-Transnacionalidade>. Acesso em: 02 ago. 2018.

SANZ, Mario Ruiz. Sociedades multiculturales y sistemas jurídicos: intersecciones y confrontaciones. Derechos y libertades, 32, 2015, p. 79-105. Doi: 10.14679/1003.

SCOTT, C. Transnational Law as Proto-Concept: Three Conceptions. German Law Journal, 10(7), 859-876. DOI: 10.2139/ssrn.1488245.

STEINER, Henry J.; VAGTS, Detlev F.; KOH, Harold H. Transnational Legal Problems: Materials and Text. 4. ed. New York: The Foundation Press, 1994.

TEUBNER, Gunther. Os múltiplos corpos do rei: a autodestruição da hierarquia do direito. In: FILOSOFIA do direito e direito econômico que diálogo? Lisboa: Instituto Piaget, 1999.

. A Bukowina Global sobre a Emergência de um Pluralismo Jurídico Transnacional. Impulso, Piracicaba, v. 14, n. 33, p. 9-32, jan./abr. 2003.

Fragmented Foundations: Societal Constitutionalism Beyond the Nation State. In: DOBNER, Petra. LOUGHLIN, Martin.(Orgs.). TheTwilightof Constitutionalism? Oxford:Oxford University Press, 2010.

TUORI, K. Transnational Law. On Legal Hybrids and Perspectivism, p. 11-57. In: MADURO, M.; TUORI, K.; SANKARI, S. (Orgs.) Transnational Law. Rethinking European Law and Legal Thinking. Cambridge: Cambridge University PressUORI, 2014.

VAGTS, Detlev F. Transnational business problems. New York: The Fundation Press, 1986.

WALLERSTEIN, Immanuel. Compreendere Il mondo. Introduzione all'analisi dei sistemi-mondo. Trieste: Saterios, 2006.

ZUMBANSEN, Peer. Transnational Law. Comparative Research in Law \& Political Economy. Research Paper No. 9/2008. Disponível em: <htp://digitalcommons.osgoode. yorku.ca/clpe/181>. Acesso em: 11 mar. 2019.

Submetido: $26 / 08 / 2019$

Aceito: $21 / 11 / 2019$ 


\title{
O DIREITO TRANSNACIONAL E A CONSOLIDAÇÃO DE UM PLURALISMO JURÍDICO TRANSNACIONAL
}

\begin{abstract}
Resumo
Este artigo, cujo objetivo é discorrer sobre o direito transnacional e a possibilidade de consolidação de um pluralismo jurídico transnacional, inicia-se com algumas considerações acerca da transnacionalidade como fenômeno caracterizador da atual sociedade mundial, adotando-se o fenômeno transnacional como ponto de partida para análise da sua dimensão jurídica. Na sequência, são apresentados questionamentos acerca das teorias monistas e dualistas, com o fito de demonstrar que as complexas redes de relações jurídicas da esfera transnacional não mais se amoldam às citadas teorias. Diante desse fato, vislumbra-se a possibilidade da construção de um pluralismo jurídico transnacional a partir do direito transnacional, totalmente diverso do pluralismo jurídico clássico. Ao final, conclui-se ser imprescindível afastar qualquer tentativa de manutenção de um pluralismo adstrito a atos jurídicos de comparação e convergência, ante a necessidade de utilizar-se também da coordenação e integração entre sistemas jurídicos e não jurídicos, elevando o desafio dos fenômenos que transcendem fronteiras e superando modelos categorizados em local, internacional, supranacional ou global. A metodologia a ser empregada compreende o método indutivo, sendo acionadas as técnicas do referente, da categoria, dos conceitos operacionais e da pesquisa bibliográfica.
\end{abstract}

Palavras-chave: Direito transnacional; monismo; dualismo; pluralismo jurídico. 


\title{
TRANSNATIONAL LAW AND THE CONSOLIDATION OF TRANSNATIONAL LEGAL PLURALISM
}

\begin{abstract}
This article, whose objective is to discuss transnational law and the possibility of consolidating a transnational legal pluralism, begins with some considerations about transnationality as a phenomenon that characterizes current world society, adopting the transnational phenomenon as a starting point for analysis of its legal dimension. In the sequence, questions are raised about monistic and dualistic theories, in order to demonstrate that the complex networks of juridical relations of the transnational sphere no longer conform to the aforementioned theories. In view of this fact, the possibility of constructing a transnational legal pluralism based on transnational law, totally different from classical legal pluralism, is envisaged. In the end, it is concluded that it is essential to remove any attempt to maintain a pluralism bound up with legal acts of comparison and convergence, in view of the need to also use coordination and integration between legal and non-legal systems, raising the challenge of phenomena that transcend borders and overcome models categorized in local, international, supranational or global. The methodology to be used includes the inductive method, being applied the techniques of the referent, category, operational concepts and bibliographic research.
\end{abstract}

Keywords: Transnational law; monism; dualism; legal pluralism. 